\title{
Application of C Language to Design Chute Spillway
}

\author{
S. S. Salunkhe ${ }^{1 *}$, P. R. Kolhe ${ }^{1}$, H. N. Bhange ${ }^{1}$, V. D. Jadhav ${ }^{2}$ and B. L. Ayare ${ }^{1}$ \\ ${ }^{1}$ SWCE, CAET, Dr. BSKKV, Dapoli Maharashtra, India \\ ${ }^{2}$ Khed, Maharashtra, India \\ *Corresponding author
}

\section{A B S T R A C T}

\section{Keywords \\ $\mathrm{C}++$, Chute spillway, CPP, ICT Tool, Information \\ Technology, Integration}

\section{Article Info}

\section{Accepted:} 04 September 2020 Available Online: 10 October 2020
Increasing of Population creates various problems regarding limited natural resources, land degradation, etc. The ICT tool is era which convenient to use of any equipment use by utilizing the programming tool. It helps in solving vast calculations work with less time i.e. it saves the time. In most of field it is used such as agriculture, irrigation, companies, colleges, disaster management, etc. This is integrated with Information technology and work through Agricultural calculations. The calculation must be fast and easy for measure the various entities in agriculture. Thus, this paper presents the design of chute spillway using ICT tool.

\section{Introduction}

A spillway is a structure used to provide the controlled release of flows from a dam into a downstream area, typically being the river that was dammed. Spillways release floods so that the water does not overtop and damage or even destroy the dam. Except flood periods, water does not normally flow over a spillway. In contrast, an intake is a structure used to release water on a regular basis for water supply, hydroelectricity generation, etc. Floodgates may be designed into spillways to regulate water flow and dam height. Other uses of the term "spillway" include bypasses of dams or outlets of a channels used during high water, and outlet channels carved through natural dams such as moraines. There are various types of spillways such as drop, ogee, chute spillway etc. that can be provided depending on the suitability of site and other parameters.

A controlled spillway has mechanical structures a controlled spillway has mechanical structures or gates to regulate the rate of flow. This design allows nearly the full height of the dam to be used for water storage year-round, and flood waters can be released as required by opening one or more gates. 
An uncontrolled spillway, in contrast, does not have gates; when the water rises above the lip or crest of the spillway it begins to be released from the reservoir. The rate of discharge is controlled only by the depth of water above the reservoir's spillway. Storage volume in the reservoir above the spillway crest can only be used for the temporary storage of floodwater; it cannot be used as water supply storage because it is normally empty.

A chute spillway is a common and basic design which transfers excess water from behind the dam down a smooth decline into the river below. Chute spillways can be ingrained with a baffle of concrete blocks but usually have a dissipater basin which creates a hydraulic jump, protecting the toe of the dam from erosion.

Agriculture is a major sector in the world. Recently, IT sector is growing exponentially. It gives various benefits effecting the growth of all sectors which includes agriculture, agriculture extension etc. Today the populations are increasing vastly which creates the problems regarding limitation of natural resources, integration of agricultural research, management, co-ordination and extension. Thus, the ICT allows the research programme managers working in national ministries and various funding agencies to achieve these problems. Though, challenge is to explore the opportunities provided by the IT revolution to ensure the sustainable and productive agriculture. So, it can be done through ICT integration into research operations, monitoring and planning if all field of agricultural production, research and extension (Kolhe et al., 2009).

The field of education has been affected by ICTs (Information and communications technology), with teaching, learning, and research (Yusuf, 2005). Various researchers have been used ICT application to design various formulae with computer based language (Salunkhe et al., 2019). In present, the advance technology of ICT make possible to recover or regain almost all information from the global source so, they are unable to access required information on the farming life cycle, seed selection, pesticides, etc. from the internet (Kokane et al., 2018). Also fast growth in the field of ICT helps in various fields like Agriculture, education, health, etc. In 2014 Kolhe et al., presenting the various role of information technology in modern irrigation sector for various purposes such as estimation of weather parameters, water availability \& water demand, gross command area, crop water requirements, crop production for different amount of water supply, to prepare water supplying scheduled, etc.

Recently various technologies are increasing rapidly to get the control of on the technical areas and bring every entity under the one roof of Information Communication Technology (ICT). Computer system is one of which become more accurate and fast. $\mathrm{C}$ and CPP are one of the most popular languages usually used with system application software, drivers, client-server applications etc. Most of the software programmes are written using CPP due to its flexibility. There are various forms of representing the equations or formulae. One of the conversions is from equation to the programme code which solves the equation. Such type of technique used to build the programme source which needed to give the solution to the problem of how to perform the calculations. Now, recently it is possible to generate the programme code automatically using various

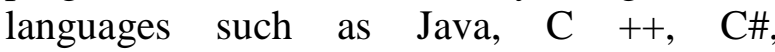
FORTRAN, etc.

$\mathrm{C}$ is programming language that helps programmers write fast, portable 
programs/code and work with it to obtain the specific output. C Language may used in various fields like library, banking, graphics, databases, applications requiring calculations, etc. $\mathrm{C}$ is one of the faster languages in the bunch of the high level programming languages and it provides excellent support. In ICT era, it is very simple to done the calculations regarding efficiency use by utilizing the programming tool. The boiler efficiency by using a C programme for various formulae is easy and accurate (Prakash Kolhe and Pradip Kolhe, 2016).

Thus, attempt has been made to simplify the calculations of designing the chute spillway using software turbo $\mathrm{C}$ with good accuracy as well as with less time. Turbo C Software is able to do $\mathrm{C}$ as well as $\mathrm{C}$ Language programs. Turbo $\mathrm{C}$ is a compiler for $\mathrm{C}$ and $\mathrm{C}++$ Language.

\section{Materials and Methods}

The design of chute spillway contains different formulas to calculate the various outputs. Also, these formulas are very complex in nature to calculate with the use of calculators manually. So it is difficult to handle the calculations manually. This may take more time and show less accuracy. Whereas, in this software developed in $\mathrm{C}$ language, these calculations are done in very less time and will have right accuracy. C program should be user-friendly and efficient to calculate the formulas of drop spillways.

This paper includes the use of $\mathrm{C}$ for calculations of chute spillways. The system is developed to reduce the Time, Wrong values, errors, complexity nature and various difficulties.

This paper involves information about how $\mathrm{C}$ software can reduces the workload, manpower and gives the accurate results of the related formulas. It also encapsulates the configuration of the system and information to design the application (Fig. 1-16).

\section{Configuration of the Developmental System}

Windows 7 ultimate

Processor: Intel (R) Core (TM) i3-3110M CPU@2.40 GHz.

Installed memory (RAM): $4.00 \mathrm{~GB}$

System type: 32 - bit Operating System

250 GB HDD Minimum

\author{
About the Platform/Configuration of the \\ User's System \\ Turbo C Compiler Version 3.0 or above \\ Processor: Intel Recommended \\ Installed memory (RAM): 4.00 GB \\ Recommended \\ System type: Windows 32/64 - bit Operating \\ System \\ 250 GB HDD Minimum Recommended
}

\section{Design of Chute Spillway}

Chute Spillway are Constructed at the gully head to convey the discharge from $\mathrm{u} / \mathrm{s}$ area of gully through a concrete or masonry open channel. A chute spillway usually requires less construction material than the drop inlet structure for the same capacity and drop. The computation is divided into following two parts.

Design Components

Design Dimensions

Design Components

Peak Discharge

$Q_{\text {peak }}=\frac{C I A}{36}$ 
Where, $\mathrm{Q}_{\text {peak }}$ is peak discharge which to be handled by the structure $\left(\mathrm{m}^{3} / \mathrm{s}\right), \mathrm{C}$ is runoff Coefficients, I is Rainfall Intensity $(\mathrm{cm} / \mathrm{h})$ and $\mathrm{A}$ is area (ha).

Width of Straight Inlet

$Q=1.77^{L H_{2}^{3}}$

Where, $\mathrm{L}$ is width of straight inlet $(\mathrm{m})$ and $\mathrm{H}$ is depth of flow (m).

Velocity of water flow at the toe

$V=\sqrt{2 g h c}$

Where, $\mathrm{V}$ is velocity of water flow $(\mathrm{m} / \mathrm{s}), \mathrm{g}$ is acceleration due to gravity (9.81) and hc is head loss $(\mathrm{m})$.

Initial Depth of Flow

$d_{1}=\frac{Q}{L V}$

Where, $d_{1}$ is initial depth of flow (m), $L$ is width of straight inlet (m).

Froude Number

$F=\frac{V}{\sqrt{g d 1}}$

Where, $\mathrm{F}$ is Froude number.

Depth of water after hydraulic jump

$\frac{d 2}{d 1}=\frac{1}{2}(\sqrt{1+8 F 2}-1)$

Where, $\mathrm{d}_{2}=$ depth of water after hydraulic jump (m).

\section{Design Components}

Height of floor and chute blocks

$H_{f}=d_{l}$

Where, $\mathrm{H}_{\mathrm{f}}$ is height of floor and chute blocks (m).

Width and spacing of the blocks

$W=0.75 d_{1}$

Where, $\mathrm{W}$ is width and spacing of the blocks (m).

Minimum distance of floor blocks from the side wall

$M_{d}=0.375 d_{1}$

Where, $M_{d}$ is minimum distance of floor blocks from the side wall (m).

\section{Height of tail water over the stilling basin}

$d_{2}^{\prime}=1.4 d_{1} F^{0.45}$

Where, $\mathrm{d}_{2}$ is height of tail water over the stilling basin $(\mathrm{m})$,

Length of stilling basin

$L_{b}=\frac{4.5 d 2}{F^{0.38}}$

Where, $L_{b}$ is length of stilling basin $(m)$.

Height of side walls and stilling basin

$J=\frac{d 2}{3}+d 2$

Where, $\mathrm{J}$ is height of side walls and stilling basin $(m)$ and $d_{2}$ is depth of water after hydraulic jump (m). 
Height of transverse sill

$S=0.07 d_{2}$

Where, $\mathrm{S}$ is height of transverse sill (m).

Free board of the side wall above the tail water

$$
f=\frac{d 2}{3}
$$

Where, $\mathrm{f}$ is free board of the side wall above the tail water $(\mathrm{m})$.

\section{Height of wing wall}

$$
H_{w}=J
$$

Where, $\mathrm{H}_{\mathrm{w}}$ is height of wing wall (m).

Source code for calculation of Design of Chute Spillway using C language

\author{
/* Peak Discharge */ \\ \#include<conio.h> \\ \#include $<$ stdio.h $>$ \\ \#include<math.h> \\ void main() \\ Float C, I, A, Q; \\ $\operatorname{clrscr}()$; \\ printf("\n\t\t *** Peak Discharge $* * * n \backslash ")$; \\ printf("Inlt Enter the value of Runoff Coefficients $\backslash \mathrm{tC}=")$; \\ scanf("\%f",\&C); \\ printf("\t Enter value of Rainfall Intensity (cm/h) $\backslash \mathrm{tI}=")$; \\ scanf("\%f",\&I); \\ printf("\t Enter value of Total Area (ha) $\backslash \mathrm{t} A=")$; \\ scanf("\%f",\&A); \\ $\mathrm{Q}=(((\mathrm{C} * \mathrm{I} * \mathrm{~A}) / 36))$ \\ printf("Inlt Peak Discharge (m3/s) =\%3.2flt",Q); \\ $\operatorname{getch}()$; \\ $\operatorname{clrscr}()$; \\ break; \\ \} \\ /* Width of Straight Inlet */ \\ \{ \\ Float Q, H, L; \\ $\operatorname{clrscr}()$; \\ printf("\n\t|t *** 2.Width of Straight Inlet *** \n"); \\ printf("\n\t Enter the value of Peak Discharge (m3/s) \tQ="); \\ scanf("\%f",\&Q); \\ printf("\t Enter the value of Depth of Flow (m) $\backslash \mathrm{tH}=")$; \\ scanf("\%f",\&H);

$$
\mathrm{L}=(\mathrm{Q}) /\left((\operatorname{pow}(\mathrm{H}, 1.5))^{*} 1.77\right) \text {; }
$$ \\ printf("\n\t Width of Straight Inlet $(\mathrm{m})=\% 5.2 \mathrm{f} ", \mathrm{~L})$; \\ getch () ; \\ break;
}


Similarly other source code has been made to get the solutions of formulae by using $\mathrm{C}$.

\section{Results and Discussion}

This chapter deals with the results obtained by calculation of the design of the chute spillway using $\mathrm{C}$. The formulas for measure the drop spillways are included in c program with syntax. The special purpose language $\mathrm{c}$ is here to fulfil the requirement of design the drop spillways.

\section{Steps to be followed}

Enter the option from 1 to 16 serially.

Give the input values.

After pressing enter key, output will be displayed.

Again press the enter key to switch over to the main page.

Follow the same procedure to design the different parameters.

Fig.1 Output of Main Page

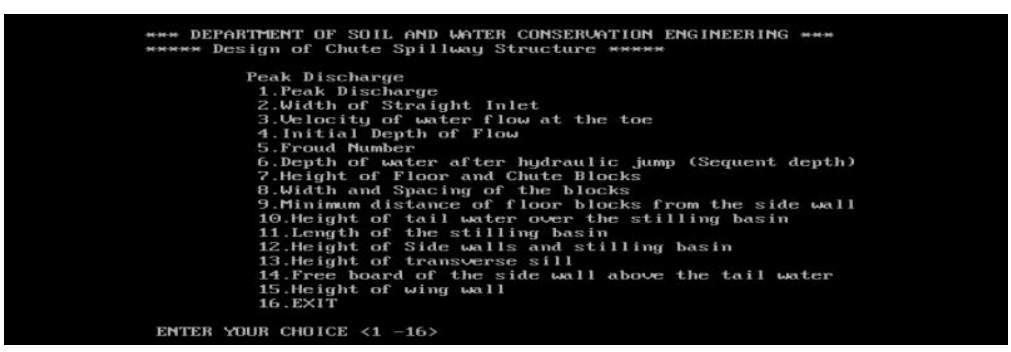

Fig.2 Output of Peak Discharge

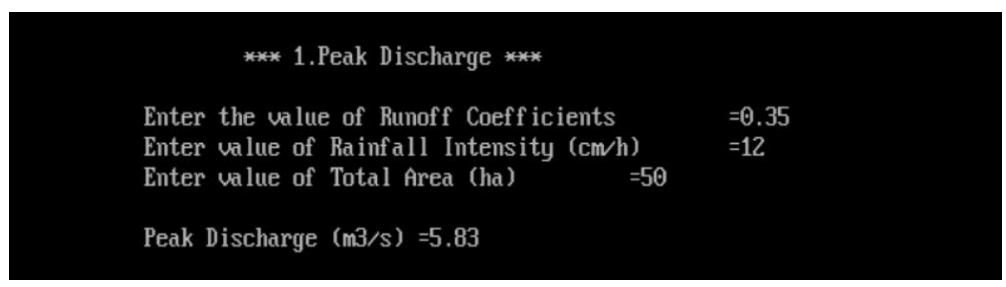

Fig.3 Output of Width of Straight Inlet

*** 2. Width of Straight Inlet ***

Enter the value of Peak Discharge (m3/s)

Enter the value of Depth of Flow $(\mathrm{m})=0.70$

Width of Straight Inlet $(m)=2.25$

Fig.4 Output of Velocity of Water at the Toe

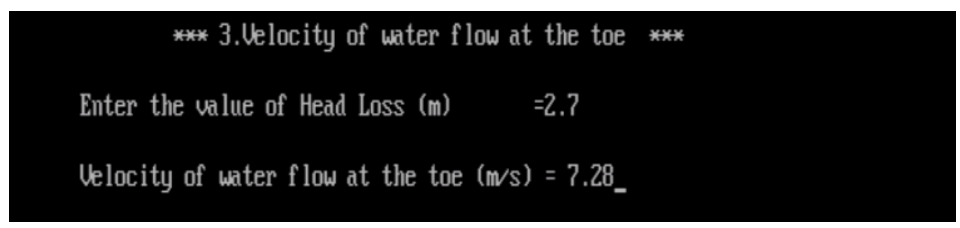


Fig.5 Output of Initial Depth of Flow

*** 4. Initial Depth of Flow ***

Enter the value of Peak Discharge ( $\mathrm{m} 3 / \mathrm{s}$ )

Enter the value of width of straight inlet ( $m$ )

Velocity of water flow at the toe $(\mathrm{m} / \mathrm{s})$

$=2.33$

$=7.28$

Initial Depth of Flow $(m)=0.14$

Fig.6 Output of Froude Number

*** 5. Proud Number ***

Enter the value of Velocity of water flow at the toe ( $\mathrm{m} / \mathrm{s}$ )

Enter the value of Initial Depth of Flow (m) $=0.142$

Froud Number $=6.17$

Fig.7 Output of Depth of Water after Hydraulic Jump

*** 6.Depth of water after hydraulic jump ****

Enter the value of Initial Depth of Flow $(m)=0.142$

Enter the value of Froud Number

$=6.166$

Depth of water after hydraulic jump $(m)=1.17$

Fig.8 Output of Height of Floor and Chute Blocks

*** 7.Height of Floor and Chute Blocks (m) ****

Enter the value of Initial Depth of Flow (m) $=0.142$

Height of Floor and Chute Blocks $(m)=0.14$

Fig.9 Output of Width and Spacing of Blocks

$$
\text { *** 8. Width and Spacing of the blocks ( } m \text { ) *** }
$$

Enter the value of Initial Depth of Flow $(m)=0.142$

Width and Spacing of the blocks $(m)=0.11$ 
Fig.10 Output of Minimum Distance of Floor Blocks from the Side Walls *** 9.Minimum distance of floor blocks from the side wall (m)

Enter the value of Initial Depth of Flow (m) $=0.142$

Minimum distance of floor blocks from the side wall $(\mathrm{m})=0.05$

Fig.11 Output of Height of Tail Water over the Stilling Basin

*** 10. Height of tail water over the stilling basin $(m) * * *$

Enter the value of Initial Depth of Flow $(m)=0.142$

Enter the value of Froude number $(m)=6.166$

Height of tail water over the stilling basin $(m)=0.45$

Fig.12 Output of Length of the Stilling Basin

*** 11.Length of the stilling basin (m) ***

Enter the value of Depth of water after hydraulic jump (m) $\quad=1.17$ Enter the value of Froude number $(m)=6.166$

Height of tail water over the stilling basin $(m)=2.64$

Fig.13 Output of Height of Side walls and Stilling Basin

*** 12. Height of Side walls and stilling basin (m) ***

Enter the value of Depth of water after hydraulic jump (m) $\quad=1.17$

Enter the value of Height of tail water over the stilling basin (m)

$=0.45$

Height of Side walls and stilling basin $(m)=0.84$

Fig.14 Output of Height of Transverse Sill

*** 13. Height of transuerse sill (m) ****

Enter the value of Depth of water after hydraulic jump (m) $\quad=1.17$

Height of transuerse sill $(m)=0.08$ 
Fig.15 Output of Free Board of the Side Walls above the Tail W

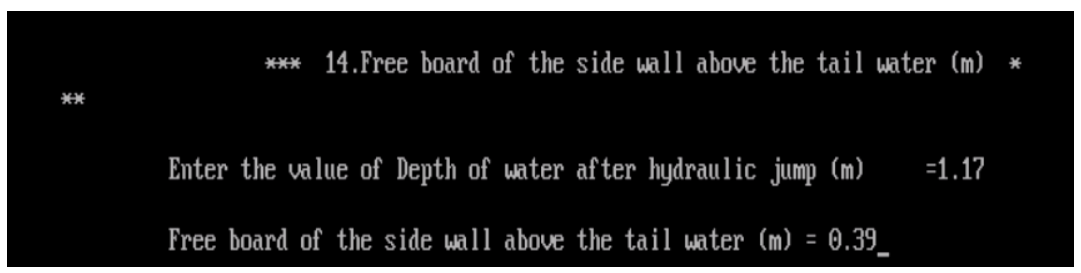

Fig.16 Output of Height of Wing Wall

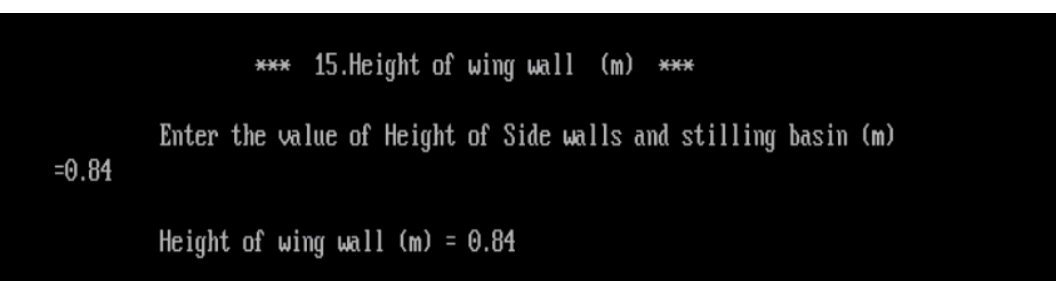

In conclusions the various formulae used to design the chute spillway such as peak discharge, width of straight inlet, velocity of water flow at the toe, initial depth of flow, Froude number, etc., were accurately determined. Also it can be done in very less time period with great accuracy. Thus, the software was found to be beneficial for determining the design of chute spillway. Thus, study concluded that the $\mathrm{C}$ language gives accurate results; it is user friendly and time efficient. Recently various technologies are increasing rapidly. Computer system is one of which become more accurate and fast. $\mathrm{C}$ is one of the most popular languages usually used with system application software, drivers, client-server applications etc. Most of the software programmes are written using $\mathrm{C}$ due to its flexibility. There are various forms of representing the equations or formulae. Thus, attempt has been made to simplify the calculations of designing the chute spillway using software turbo $\mathrm{C}$ with good accuracy as well as with less time. The design of chute spillway contains different formulas to calculate the various outputs. Also, these formulas are very complex to calculate with the use of calculators manually. Sometimes it is necessary to save the data of calculations with their formulae. So, it is very difficult to store it in register notebooks. It is very difficult to keep and handle that registers manually year over years.

Therefore, it is difficult to handle the calculations manually. This may take more time and show less accuracy. Whereas, in this software developed in C language, these calculations are done in very less time and will have right accuracy. $\mathrm{C}$ program should be user-friendly and efficient to calculate the formulas of drop spillways. $\mathrm{C}$ is the special purpose language to fulfil the requirements of the special code or system.

\section{References}

Blaisdell, F.W. 1948. The SAF Stilling Basin. The Agricultural Hand book no 156, USDA.

Kokane, G. K., Kolhe, S. R., Labade, D. M. and Vaidya, G. B. 2018. Krishi-Mitra:An ICT enabled Interface for Farmers. IJARIIE, 4(3), 1676-1680.

Kolhe P. R., Kolhe P. P. and M. H. Tharkar. 2009. Information and communication technology emerging tool for agricultural Extension. Asian Sciences, 4(1\&2), 85-90.

Kolhe, P. R., Kolhe, P. P. and Tharkar, M. H. 
2014. Role of Information Technology in Modern Irrigation Sector (An emerging dimension in IT). 2014. IPASJ International Journal of Information Technology (IIJIT), 2(10), 1-3.

Kolhe, P. R. and Kolhe, P. P. 2016. Computer Programming Tool ('C' Program) To Determine Boiler Efficiency. International Journal of Mathematics and Computer Applications Research (IJMCAR), 6(2), 33-42.

Salunkhe, S. S., Kolhe, P. R., Nandgude, S. B., Jadhav, V. D. and Bhange, H. N. 2019. ICT application to design of drop spillway with GUI. The Pharma
Innovation Journal, 8(11): 195-200.

Taubert U. (1974). the design of spillway contractions using computer simulation, wat. Pwr dam constr, Pp. 282-28.

U.S.B.R. 1965. Design of Small Dams (Government printing office).

Ven Te Chow. 1959. Open-Channel Hydraulics, McGraw-Hill Civil Engineering Series.

Yusuf, M. O. 2005. Information and communication education: Analysing the Nigerian national policy for information technology. International Education Journal, 6(3): 316-321.

\section{How to cite this article:}

Salunkhe, S. S., P. R. Kolhe, H. N. Bhange, V. D. Jadhav and Ayare, B. L. 2020. Application of C Language to Design Chute Spillway. Int.J.Curr.Microbiol.App.Sci. 9(10): 399-408. doi: https://doi.org/10.20546/ijcmas.2020.910.049 